\title{
Neonatal Hypoxic Ischemic Encephalopathy
}

National Cancer Institute

\section{Source}

National Cancer Institute. Neonatal Hypoxic Ischemic Encephalopathy. NCI Thesaurus. Code C119751.

Injury to the central nervous system in the newborn period that occurs when there is insufficient delivery of oxygen to all or part of the brain. 